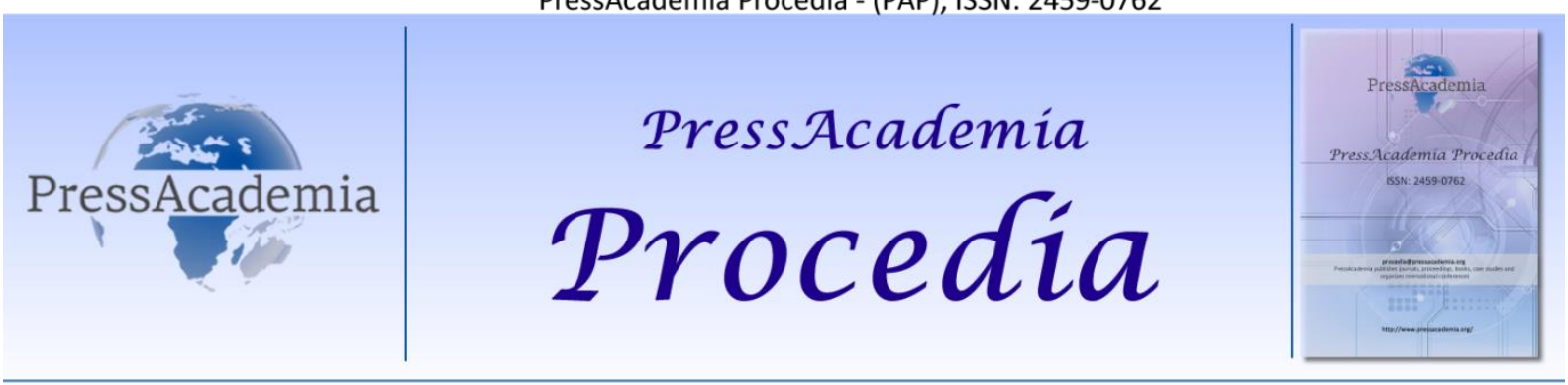

2nd World Conference on Technology, Innovation and Entrepreneurship

May 12- 14, 2017, Istanbul, Turkey. Edited by Sefer Şener

\title{
DEVELOPMENT OF A HYBRID MODEL TO QUANTIFY THE SINGLE AND DOUBLE STRAND BREAKS FOLLOWING THE IRON 57 DE-EXCITATION
}

\author{
DOI: 10.17261/Pressacademia.2017.583 \\ PAP-WCTIE-V.5-2017(21)-p.143-152
}

H.Oudira ${ }^{1}$, D. Lotfi ${ }^{1}$, A.Saifi ${ }^{2}$

${ }^{1}$ Faculty of Technology, Department of Electronics University Mouhamed Boudiaf of M'Sila , Algeria. Oudira houcine@yahoo.fr

${ }^{2}$ Faculty of Technology, Department of Electronics University Mouhamed Boudiaf of M'Sila, Algeria. lotfi djouane@yahoo.fr

${ }^{3}$ Faculty of Engineering Department of Electronics University of Constantine 1, Algeria. Saifi19@yahoo.fr

\section{ABSTRACT}

The therapeutic utility of certain Auger emitters such as iodine-125 depends on their position within the cell nucleus. Or diagnostically, and to maintain as low as possible cell damage, it is preferable to have radionuclide localized outside the cell or at least the core. One solution to this problem is to consider markers capable of conveying anticancer drugs to the tumor site regardless of their location within the human body. The objective of this study is to simulate the impact of a complex such as bleomycin on single and double strand breaks in the DNA molecule. Indeed, this simulation consists of the following transactions: Construction of BLM -Fe- DNA complex, simulation of the electron's transport from the metastable state excitation of Fe 57 by the Monte Carlo method, treatment of chemical reactions in the considered environment by the diffusion equation. For physical, physico-chemical and finally chemical steps, the geometry of the complex is considered as a sphere of $50 \mathrm{~nm}$ centered on the binding site, and the mathematical method used is called step by step based on Monte Carlo codes.

\section{INTRODUCTION}

The toxicity of Auger emitters, such as iodine-125 is dependent on their position within the cell nucleus [1]. Thus, to reach the tumor cells, targeting agents that connect selectively to the double helix of the DNA molecule is used [2]. This is the case of bleomycin associated with a metal and an oxidant will be able to catalyze DNA strand breaks [3].

Indeed, the complex (HOO-Fe (III) BLM) said "activated bleomycin" is responsible for strand breaks induced on sites guanine-cytosine and / or guanine-thymine. In addition, it is postulated that this complex is the only active compound in vivo [4], which justifies the appropriateness of this study to compare the results obtained with those deduced from the radio-induced damage simulation by the disintegration of iodine 125 situated in chromosomal fiber [1].

The rest of this paper is organized as follows. In section 2 and 3 we introduce the problem position and the mathematical models used respectively. In section 4 presents the data used to solve the problem. The application, results and discussion are the aim of the sections 5 and 6 . Finally, in the last section we present our conclusion and potential future work.

\section{PROBLEM POSITION}

To simulate the primary physical processes relative to a passage of an ionizing radiation through a biological medium; the Monte Carlo method of the type step by step which aims to reproduce the randomness of interactions [5] is used. Thus, software for tracing the full path target of an incident electron and secondary created through a DNA are developed. This work is firstly to be considered as a sequence of events leading to breakage of the strand as shown in Figure 1 , and also to develop codes based on the excitation of the iron 57 incorporated in the DNA molecule. Indeed, this radionuclide emits by de-excitations a series of low-energy electrons, causing damage near to the site of decay. To reduce the computation time associated with the stochastic approach, we simulate the indirect effect of de-excitations through the diffusion equation [6-7]. 
Figure 1: Sequence of Events Leading to Strand Breaks

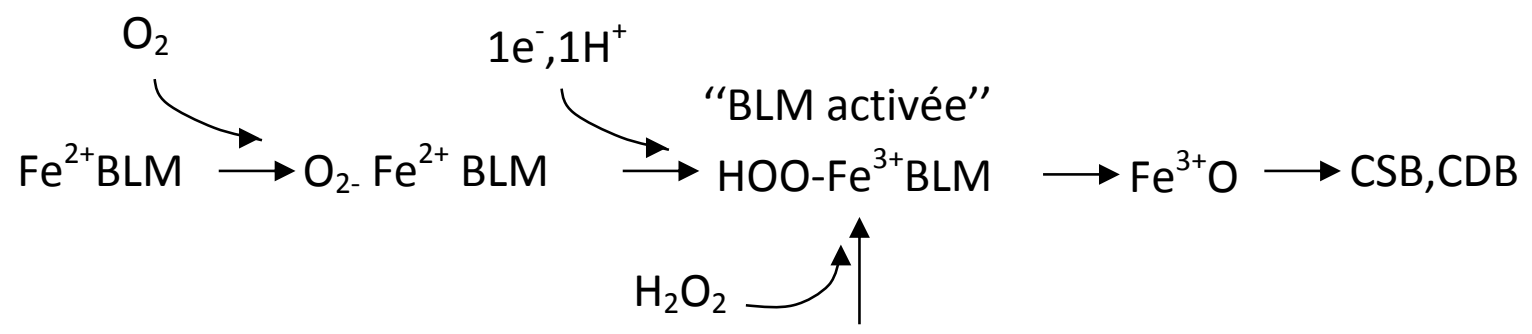

$\mathrm{Fe}^{3+} \mathrm{BLM}$

\section{MATIMATICAL MODELS}

\subsection{Stochastic Model of Monte Carlo}

The Monte Carlo method of the type step by step is adapted perfectly to the study of the physical and physic-chemical evaluation phases of the energy deposited in the target volume, to the extent that we consider the path $\lambda$ that an electron can traverse in a heterogeneous milieu and the probability of interaction with a given entity.

$$
\lambda=-\overline{\lambda(E)} \cdot \log R
$$

$\overline{\lambda(E)}$ is the range and is given by the relation:

$$
\overline{\lambda(E)}=\frac{1}{\sum_{i j} N_{i} \sigma_{i j}(E)}
$$

Where: $R$ is an arbitrary number equally distributed between 0 and 1 .

$N_{i}$ is the number of atoms or molecules of the type $i$ by unit of volume.

$\sigma_{i j}(E)$ is the effective section of interaction of the type $j$ on the atom or the molecule of the type $i$ for an incidental particle of energy $E$.

$$
P_{i}=\sigma_{i}(E) \cdot N_{i} \cdot \overline{\lambda(E)}
$$

$P_{i}$ is the probability for that an incidental particle interacts with an atom or a molecule of the $i$ component, knowing that there is interaction.

If there are $k_{i}$ types of different interactions from the incidental particle with the $i$ component, the $j$ type of interaction having an effective section total $\sigma_{i j}(E)$ by atom or by molecule, the probability so that the interaction is of the type $j$, knowing that the interaction takes place with the $i$ component, is thus :

$$
P_{i j}=\frac{\sigma_{i j}(E)}{\sum_{l=1}^{k} \sigma_{i l}(E)}
$$

During simulation, the point of interaction being fixed, we will have an interaction with the $i$ component if $i$ verifies:

$$
\sum_{l=1}^{i-1} P_{l}<R_{1} \leq \sum_{l=1}^{i} P_{l}
$$


and the interaction will be of the type $j$ on the $i$ component if $j$ verifies:

$$
\sum_{l=1}^{j-1} P_{i l}<R_{2} \leq \sum_{l=1}^{j} P_{i l}
$$

$R_{1}$ and $R_{2}$ are arbitrary numbers equally distributed between 0 and 1 .

At the end of the physical stage $\left(10^{-15}\right.$ Second) the irradiated molecules are in an excited or ionized state [7] whose fate is drawn by probabilities indicated above.

at $10^{-12}$ second, the electronic trace produced, in its neighbor, the chemical species such as :

$$
e_{a q}^{-}, \mathrm{H}, \mathrm{OH}, \mathrm{H} 2, \mathrm{H} 2 \mathrm{O} 2 \text {, and } \mathrm{H}_{3} \mathrm{O}^{+} \text {. }
$$

With regard to, the cross sections of biological interest molecules [8], we adopted the correction introduced by Laverne and Pimblott [9].

$$
\sigma_{D N A}=\frac{A_{D N A}}{A_{\text {water }}} \cdot \sigma_{\text {water }}
$$

Where $A_{D N A}$ and $A_{\text {water }}$ are respectively the molar masses of the DNA and water.

Each atom of the DNA is differentiated from the other atoms by introduction of an empirical grandeur known as ray of Van Der Waals (RVDW). The total cross section $\sigma_{i}$ of an atom of VDW RVDW's ray is written:

$$
\sigma_{i}(E)=\frac{R_{V D W}^{i}}{\sum_{\text {Base }} R_{V D W}^{i}} \frac{A_{\text {Base }}}{A_{\text {water }}} \sigma_{\text {xater }}
$$

Thus, we exploited the rays of VDW presented by Burkert [10] for the simulation of the electrons transport in the biological environment.

\subsection{Diffusion Equation}

To reduce the calculating time machine, relating to the study of the chemical phase, we chose a deterministic approach based on the resolution of the diffusion equation [ 11 ].

$$
\frac{\partial C_{i}}{\partial t}=D_{i} \nabla^{2} C_{i}+S
$$

- $C i$ is the concentration of the species of the type $i\left(\right.$ mole $\left.^{-3}\right)$

- $D_{i} \nabla^{2} C_{i}$ is the product of the Laplacian of $C_{i}$ by the constant of diffusion $D_{i}\left(\mathrm{~cm}^{2} \mathrm{~s}^{-1}\right)$ of the species of the type $i$;

- $S$ is the term source (mole $\mathrm{dm}^{-3} \mathrm{~s}^{-1}$ ), considered as the algebraic sum of terms representing, following the chemical reaction taken in consideration, the impoverishment or the production of the species of the type $i$ :

$$
S=\left(\sum_{w} k_{i w} C_{w}+\sum_{l} \sum_{j} k_{l j} C_{l} C_{j}\right)-\left(k_{i} C_{i}+\sum_{j} k_{i j} C_{i} C_{j}\right)
$$

$k_{i w} C_{w}, k_{l j} C_{l} C_{j}$ represent respectively the production of species $i$ following the dissociation of w, and the reaction of the species / with the species $j . k_{i} C_{i}$ and $k_{l j} C_{l} C_{j}$ represent respectively the impoverishment of species $i$ following its dissociation, and its reaction with the particles of the type $j ; k_{i w} k_{i}, k_{l j}$ and $k_{i j}$ indicate the constants of reaction's speed; $k_{i w}$ and $k_{i}$ are expressed in $\mathrm{s}^{-1}$, while $k_{l j}$ and $k_{i j}$ are in $\mathrm{dm} 3 \mathrm{~mole}^{-1} \mathrm{~s}^{-1}$. 


\subsubsection{Discretizing the Diffusion Equation}

To solve the equation (9), it is necessary to discretize it, that is to say, to replace it by simple algebraic equations expressing the same physical information that can be solved numerically. For this, converts the equation (9) in an integral equation by applying the weighted residuals method:

$$
\iiint \int \frac{\partial C_{i}}{\partial t} W(X, Y, Z, t) d X d Y d Z d t=\iiint \int\left(D_{i} \nabla^{2} C_{i}+F\right) W(X, Y, Z, t) d X d Y d Z d t
$$

The choice of the test function $W(X, Y, Z, t)$, and integration of equation (11) cause algebraic equations such that the concentration $C_{i}$ in a point $\mathrm{P}\left(C_{i p}\right.$ noted), the center of a elementary volume within the computational domain, is connected to those of the points $E, W, R, Q, S$, and $N$ center of neighboring elementary volumes considered (Figure 2).

\section{Figure 2: Immediate Neighboring of an Elementary Volume Inside the Three-Dimensional Grid}

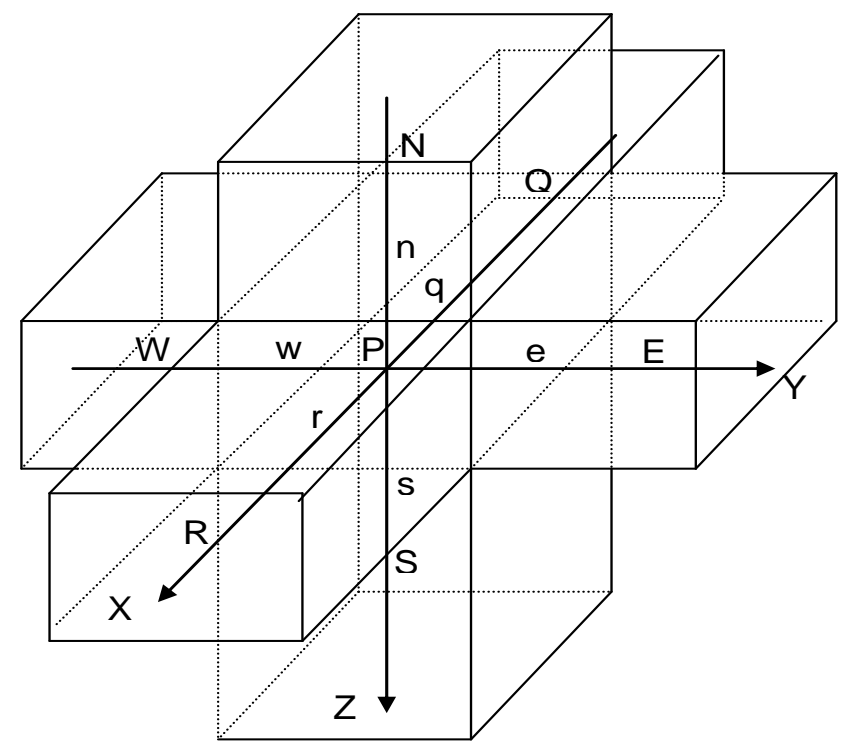

To access this formulation we have used the continuous finite element method [12], [13] and the method of centered differences [10]. Thus, the explicit method can replace the equation (11) by the following algebraic equation:

$$
A_{P} C_{i P}=A_{E} C_{i E}+A_{W} C_{i W}+A_{R} C_{i R}+A_{Q} C_{i Q}+A_{S} C_{i S}+A_{N} C_{i N}+K
$$

\subsubsection{Calculation of Equation (12) Coefficients}

For a point $\mathrm{P}$ situated inside the three-dimensional grid, integrating (11) on the following ranges:

$[t ; t+\Delta t],\left[X_{P}-\frac{\Delta X}{2} ; X_{P}+\frac{\Delta X}{2}\right],\left[Y_{P}-\frac{\Delta Y}{2} ; Y_{P}+\frac{\Delta Y}{2}\right],\left[Z_{P}-\frac{\Delta Z}{2} ; Z_{P}+\frac{\Delta Z}{2}\right]$

provides the coefficients $A_{P}, A_{E}, A_{W}, A_{R}, A_{Q}, A_{S}, A_{N}$ and $K$ relating to the equation (12) and whose values:

$$
\begin{aligned}
& \mathrm{A}_{\mathrm{E}}=\mathrm{D}_{\mathrm{i}} \frac{\Delta \mathrm{X} \Delta \mathrm{Z}}{\Delta \mathrm{Y}}=\mathrm{A}_{\mathrm{W}} \\
& \mathrm{A}_{\mathrm{R}}=\mathrm{D}_{\mathrm{i}} \frac{\Delta \mathrm{Y} \Delta \mathrm{Z}}{\Delta \mathrm{X}}=\mathrm{A}_{\mathrm{Q}} \\
& \mathrm{A}_{\mathrm{S}}=\mathrm{D}_{\mathrm{i}} \frac{\Delta \mathrm{X} \Delta \mathrm{Y}}{\Delta \mathrm{Z}}=\mathrm{A}_{\mathrm{N}} \\
& \mathrm{A}_{\mathrm{P}}=\frac{\Delta \mathrm{X} \Delta \mathrm{Y} \Delta \mathrm{Z}}{\Delta \mathrm{t}}+\mathrm{A}_{\mathrm{E}}+\mathrm{A}_{\mathrm{W}}+\mathrm{A}_{\mathrm{R}}+\mathrm{A}_{\mathrm{Q}}+\mathrm{A}_{\mathrm{S}}+\mathrm{A}_{\mathrm{N}}
\end{aligned}
$$


$\mathrm{k}=\frac{\Delta \mathrm{X} \Delta \mathrm{Y} \Delta \mathrm{Z}}{\Delta \mathrm{t}} \mathrm{C}_{\mathrm{iP}}^{0}+\mathrm{F}_{\mathrm{P}}^{0} \Delta \mathrm{X} \Delta \mathrm{Y} \Delta \mathrm{Z}$

$\Delta \mathrm{X}, \Delta \mathrm{Y}, \Delta \mathrm{Z}$ are spaces step in the three directions of the three-dimensional grid.

$\Delta \mathrm{t}$ is the time after which the changes in the concentration of a given radiolytic species are evaluated. The boundary conditions on the extreme points of the domain used to associate their coefficients whose value varies according to the position of the elementary considered volume [10]. Following integration of equation (11) on all the elementary volumes of space concentrations, we obtain another matrix system by block, whose resolution by the method of generalized Thomas matrix calculation (called TDMA) is immediate [14]. Also, we give a detailed attention to the calculation of the space step $\Delta x$ whose value is reported with the temporal step $\Delta t$ to ensure the stability of the solutions of the equation of diffusion, to respect the electronic balance of the milieu as much as that are possible. This relation uses the constant of diffusion $\mathrm{D}$ of the fastest particle $\left(H_{a q}^{+}\right) . \quad(\Delta x)^{2} \geq \sqrt{4 D} \cdot \Delta t$

\section{DATA OF THE PROBLEM TO BE TREATED}

\subsection{BLM-Fe-DNA Complex}

It is with regard to the DNA molecule, an octamer histonnes which may be considered as a kind of bobbin around which have two supercoils of a left DNA's supercoiled. The whole forms a disc diameter of about $110 \AA, 57 \AA$ of thickness, and average step (step between two successive turns 27-28Å) [8] and [9]. Bleomycin was built of bioplymer module molecular modeling software MSI, and iron was added and conformation of bleomycin modified to fulfill with the distances and angles listed in Table 1. The entire complex was then minimized by applying the algorithm of maximum slope and the conjugates gradients to keep geometry similar to that taken as a reference [10]. The iron atom is then excited to cause a jet of Auger electrons and increase the effectiveness of bleomycin in terms of single and double strand breaks (CDB and CSB) of the DNA molecule. It's called the Mossbauer Effect and Nuclear Resonance Gama (RGN).

Table 1: Parameters Used for the Minimization of BLM-Fe-DNA Complex

\begin{tabular}{|l|c|}
\hline Total atoms Number & 16302 \\
\hline Van Der Waals Truncation (VDW) & $15 \AA$ \\
\hline Minimization algorithm & $\begin{array}{c}\text { Greater slope (500 steps) } \\
\text { Conjugate Gradient (2000 steps) }\end{array}$ \\
\hline convergence criterion & $\mathrm{RMS}=24 \mathrm{kcal} \mathrm{mol}^{-1} \AA^{-1}$ \\
\hline Initial potential energy & $610^{6} \mathrm{kcal} \mathrm{mol}^{-1}$ \\
\hline Final potential energy & $62400 \mathrm{kcal} \mathrm{mol}^{-1}$ \\
\hline Time calculation machin & $1 \quad$ Day \\
\hline
\end{tabular}

\subsection{Total and Differential Effective Sections.}

The total and differential effective sections are given in the form of curves which can be seen in figures 3 and 4 . Indeed, the effective sections are calculated here according to the energy of the electrons emitted by $57 \mathrm{mFe}$ de-excitation. This energy range of $10 \mathrm{eV}$ to $100 \mathrm{eV}$. 
Figure 3: Total atomic cross sections 10 and $1000 \mathrm{eV}$

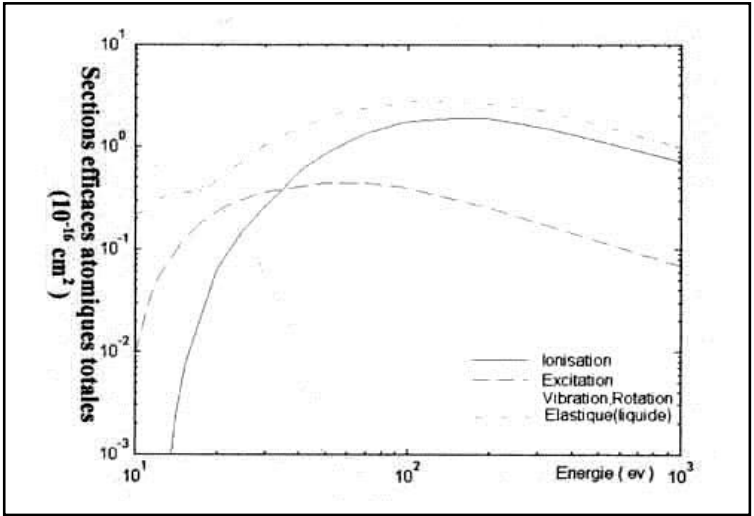

Figure 4. Echontionnage of the differentia cross between section I as a function of energy

\subsection{The $57 \mathrm{mFe}$ De-excitation Spectra}

The $57 \mathrm{mFe}$ de-excitation spectra are those obtained by Charlton [11] and Pomplun [12]. For both cases we have retained the part of the spectrum where the energy of the emitted electrons is between $1 \mathrm{eV}$ and $100 \mathrm{eV}$.

\subsection{Coefficients of Diffusion and Chemical Reactions.}

The created radiolitic species diffuse and react with molecules of biological interest. The values of the coefficients of diffusion and reaction rate constants are those given by Vrigneaud [10].

\section{PUTTING IN COMPUTER FORM}

The simulation of the diffusion and reaction processes of the radiolytic species until a time noted tmax is given by the flowchart in [1]. Indeed, a main program based upon three subroutines of space discretization, calculation of the concentrations and the radiochemical yields, and the system compression is developed. It is useful to note that the adoption of a logarithmic temporal step $\Delta t$ is in adequacy, on the one hand with the taking in consideration of the whole of the chemical reactions of the radiolytic species at the beginning of the chemical phase, and on the other hand with the evolution of the species having the greatest constant of diffusion $\left(H_{a q}^{+}\right)$at the end of the this same stage. Thus, to the injection of a temporal step $\Delta t$ corresponds the calculation of the equation coefficients (12) to the level of all elementary volumes constituent the three-dimensional grid and consequently the concentrations of all the species; this enables us to deduce the yields by using the equation (14). In our case, $N_{i}$ was defined by the following relation:

$$
N_{i}=\left[\sum_{k} \sum_{l} \sum_{m} C_{i}(k, l, m, t)\right] \cdot(\Delta x)^{3}
$$

When the computer system reaches its limits of managing different files, it uses the compression subroutine that recalculates the appropriate spatial step $\Delta \mathrm{x}$ and deduces $\Delta \mathrm{t}$ that need to inject. It is true that this procedure leads to an inaccuracy in the spatial location of the particles in question, but has the advantage of being able to continue our calculations until a time tmax

\section{RESULT AND DISCUSSION}

The choice of the spatial step $\Delta x$ depends on the value of the temporal step $\Delta t$ and therefore by accuracy and stability of the solutions of the diffusion equation (12).

The spatial discretization subroutine calculates the optimum step space from the Cartesian coordinates of the various radiolytic species from the physical and physico-chemical phases and deduces the initial concentrations at time $10^{-12} \mathrm{~s}$. To illustrate the importance of the finesse in solving the diffusion equation, we present in Figures 5,6 and 7 radiochemical yields of major radiolytic species $\left(\mathrm{OH}, e_{a q}^{-}, \mathrm{H}\right)$ and for $\Delta \mathrm{x}=10 \AA, \Delta \mathrm{t}=\left\{10^{-10} \mathrm{sec} ; 10^{-11} \mathrm{~s} ; 10^{-12} \mathrm{~s}\right\}$. 
When $\Delta t=10^{-10} \mathrm{~s}$, the relation (13) does not hold, and thus the yields are oscillating curves without any possible meaning to be interpreted. For $\Delta t=10^{-11} \mathrm{~s}$, the relation (13) holds, however the yields are fairly flat. The temporal step is too large, which results in the failure to take into account a number of reactions. Finally, when $\Delta t=10^{-12} \mathrm{~s}$, the yields obtained are comparable to those obtained from other models (Vrigneaud 2000). To optimize machine time calculation, we adopted a logarithmic time step in line with the process of diffusion and reaction of radiolytic species. In figure 8, it can be seen, for $e_{a q}^{-}$a clear concordance between our results (they have been derived based on the spectra Pomplun et al (1987) or Charlton and Humm (1985)) with those of Vriggneaud [10]. It is clear that the spectrum of Pomplun led to the formation of more of $e_{a q}^{-}$because of the electrons number of very low energy that it contains.

The yields obtained from the deterministic method are comparable to those deduced from the stochastic model taking into account the statistical fluctuation (Figure 9). Besides this similarity between results (yields) from the two approaches is confirmed when calculating simple and double strand breaks in the DNA molecule. Indeed, Figures 10 and 11 show the same tendency to increase when the energy of the electrons from the de-excitation of $57 \mathrm{mFe}$ increases.

Figure 5: Radiochemical yields of $\mathrm{OH}, \mathrm{H}$ and $e_{a q}^{-}$according to the time for an electron incident $700 \mathrm{eV}$ in liquid water $\left(\Delta t=10^{-10} \mathrm{~s}\right)$.

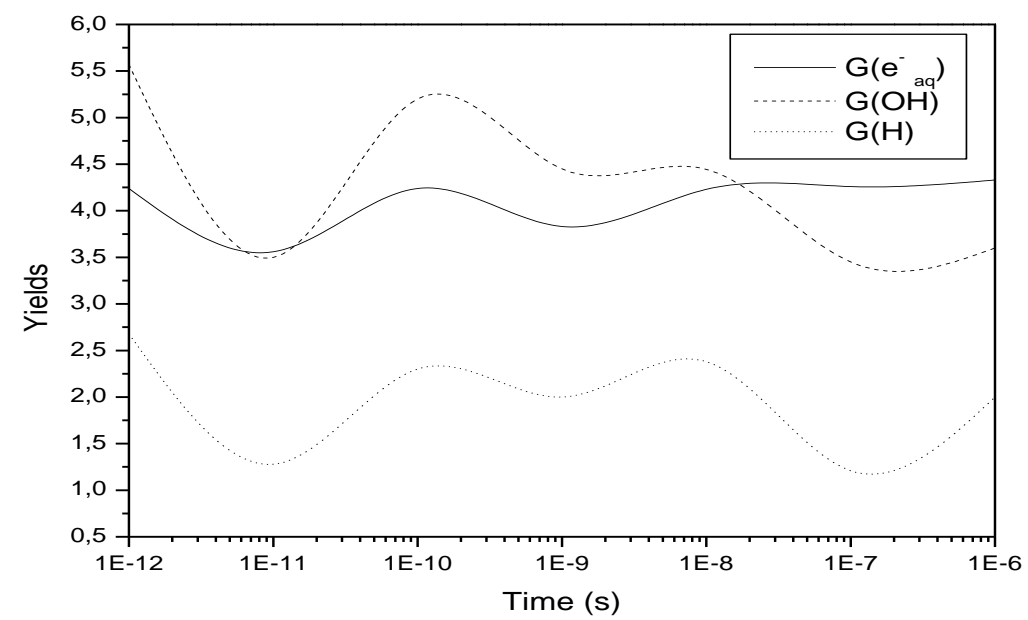

Figure 6: Radiochemical yields of $\mathrm{OH}, \mathrm{H}$ and ${ }^{e_{a q}^{-}}$according to the time for an electron incident $700 \mathrm{eV}$ in liquid water $(\Delta t=10-11 \mathrm{~s})$.

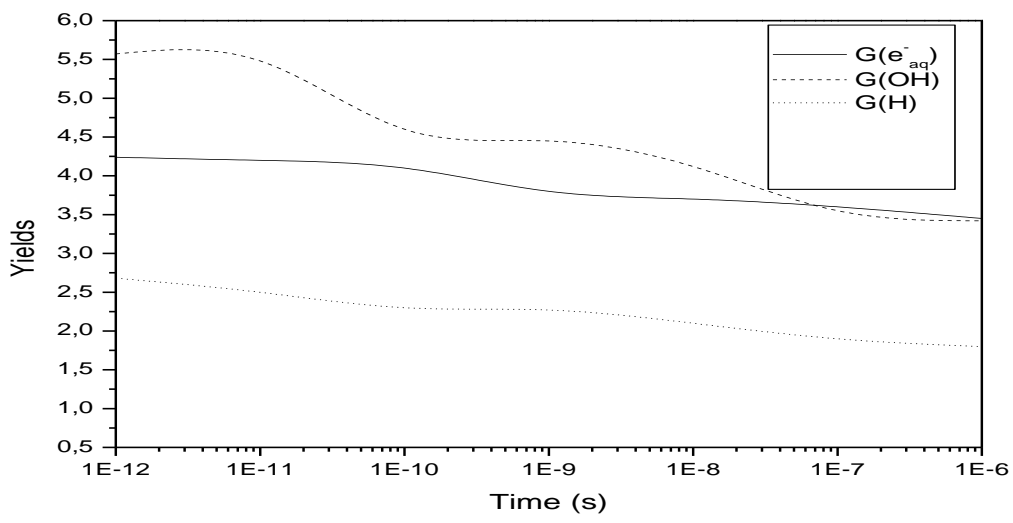


Figure 7: Radiochemical yields of $\mathrm{OH}, \mathrm{H}$ and $e_{a q}^{-}$according to the time for an incident electron of $700 \mathrm{eV}$ in liquid water $(\Delta \mathrm{t}=10-12 \mathrm{~s})$.

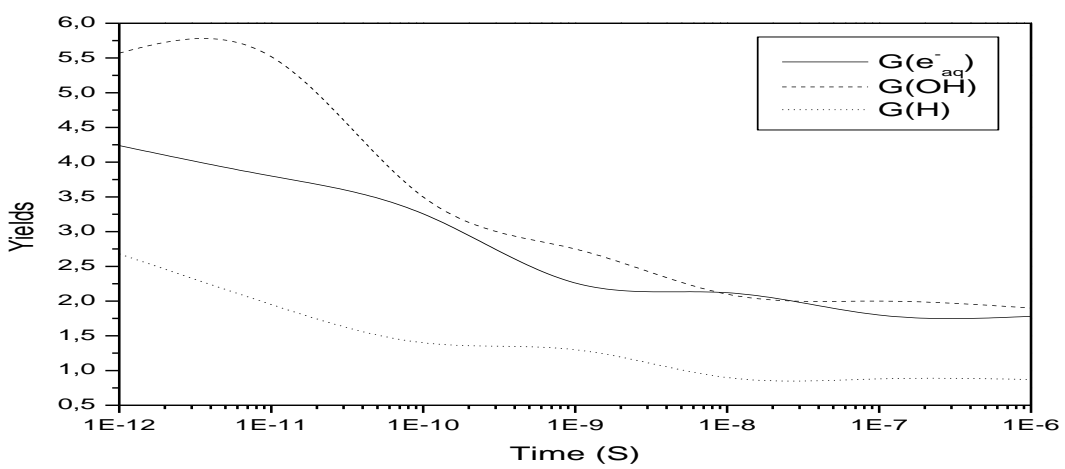

Figure 8: Comparison of yields $e_{a q}^{-}$with other models

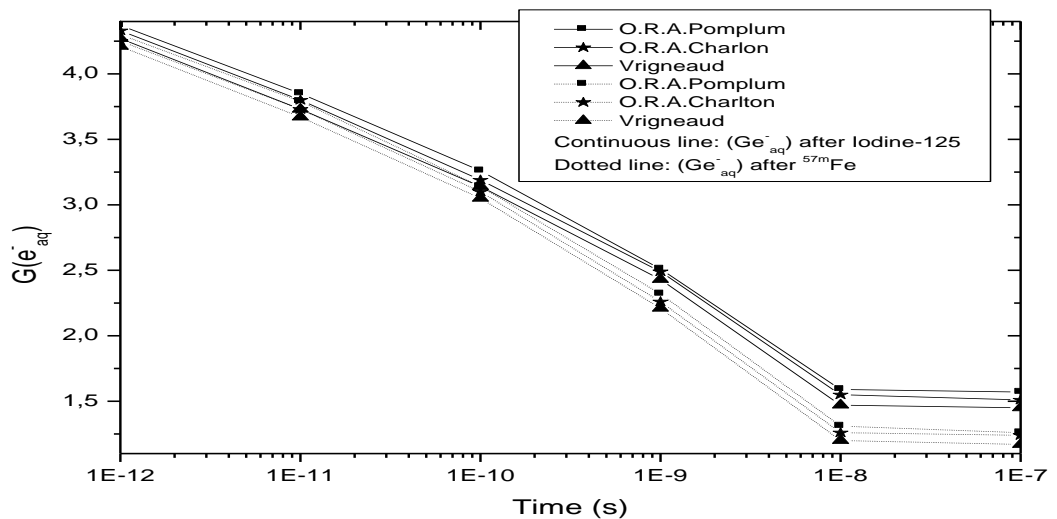

Figure 9: Variation of $\mathrm{G}\left({ }^{e_{a q}^{-}}\right)$as a function of time

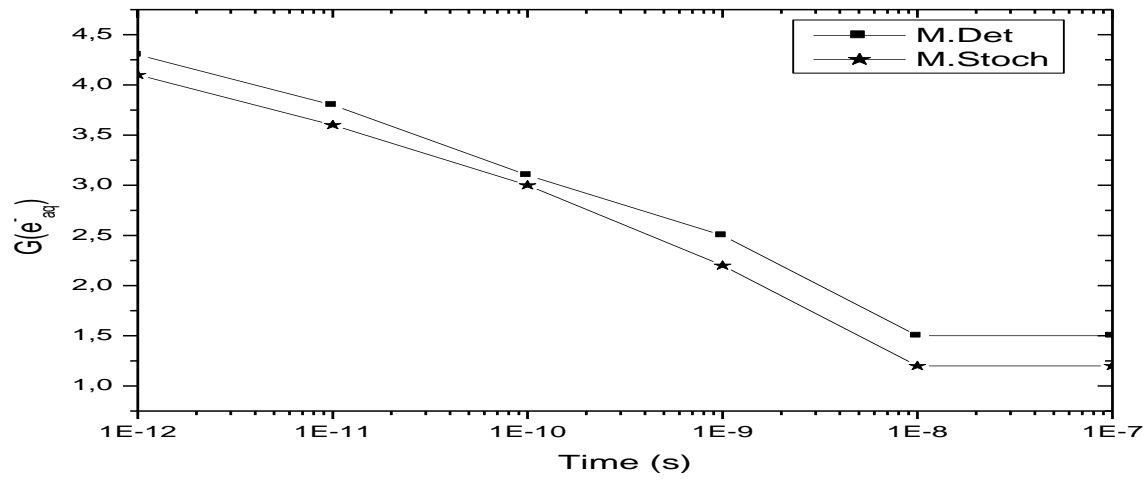


Figure 10: Yield of simple-stranded breaks according to the energy of emitted electrons by the excitation of $57 \mathrm{mFe}$

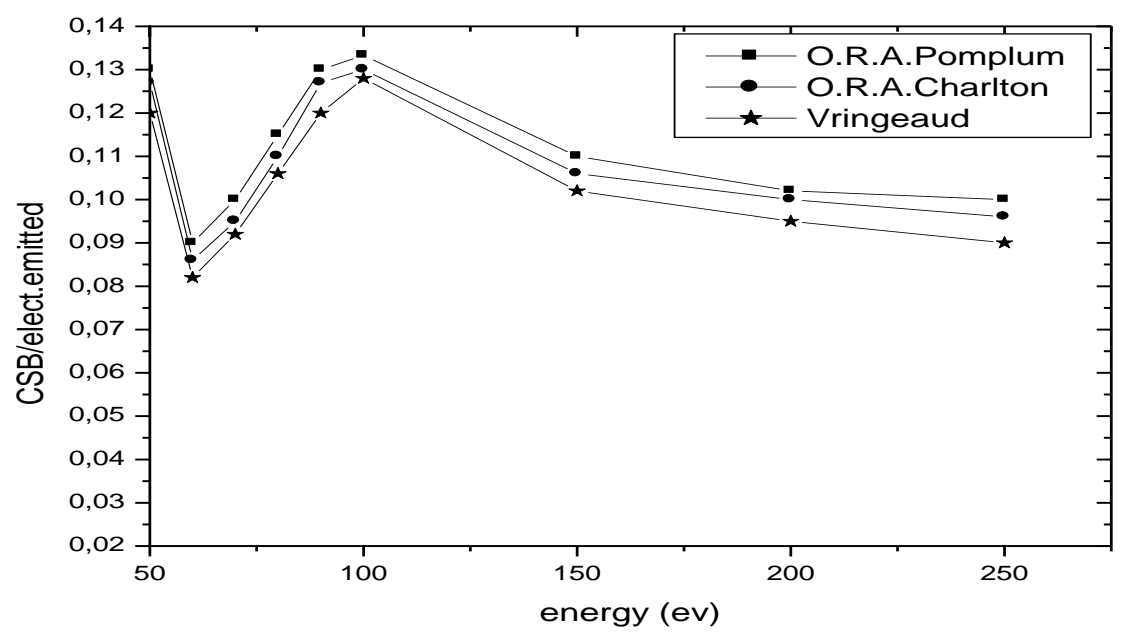

Figure 11: Yield of double strand breaks as according to the energy of emitted electrons by the excitation of $57 \mathrm{mFe}$

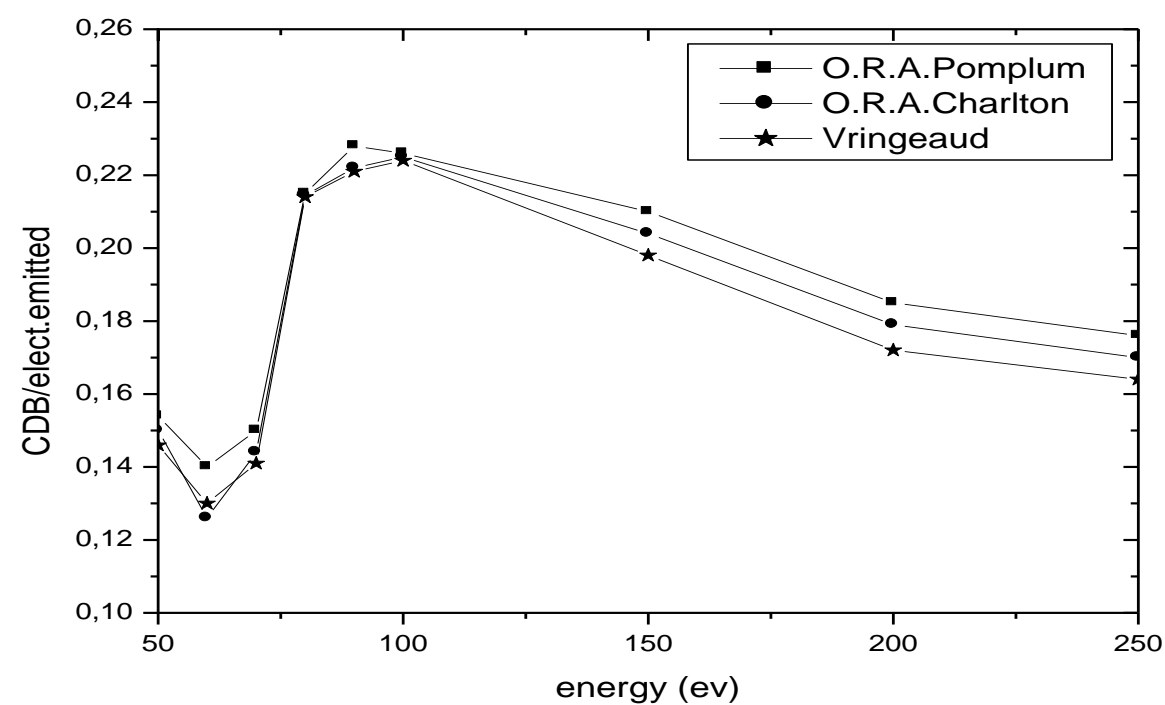

\section{CONCLUSION}

Through the data necessary for the simulation of damage radiation induced by electrons after the de-excitation of the iron 57 to the DNA molecule through the diffusion equation, we can notice that:

Our results are comparable to those obtained by the Monte Carlo method of type step by step. Furthermore, we show the inefficiency of analytical methods in the time interval $\left[10^{-12} \mathrm{~s}, 10^{-6} \mathrm{~s}\right]$ where the concentrations of radiolytic species are very unstable because of the numerous chemical reactions between radicals and subunits of DNA molecule. The developed software programs are powerful enough to the extent where we can integrate multiple parameters that can 
affect the performance of breakages caused to the DNA molecule. Indeed, it may include several $57 \mathrm{mFe}$ sources for irradiating one or more cells.

\section{REFERENCES}

[1]- Oudira H., Saifi A., "Quantification of the simple and double strand breaks following the disintegration of lodine 125 in situ in chromosomal fiber", Radioprotection, vol. 45, pp. 389-408, 2010.

[2]- Panyutin I.G., Neuman R.D., "Sequence-specific DNA breaks produced by triplex directed decay of iodine 125 ", Acta oncologica, vol. 35(7), pp. 817-823, 1991.

[3]- Burger R.M., Peisach J. et Horuvitz S.B., "Activated bleomycin: Atransient complex of drug, iron and oxygen that degrades DNA", Biol.chem, vol. 256(22), pp. 11636-11644, 1981.

[4]- Absalon M.J., Stuble.J. et Kozarich J.W., "Sequence specific double-strand cleavage of DNA by Fe-Bleomycin.1. The detection of sequence specific double strand breaks using hairpin oligonucleotides", Biochemestry, vol. 52, pp. 2065-2075, 1995.

[5]- Terrissol M., Pomplum E., "Computer simulation of DNA incorporated I ${ }^{125}$ auger cascades and of the associated radiation chemistry", radiat, Prot. Dos., vol. 52, pp. 177-181, 1994.

[6]- Djamai D., Oudira H., Saifi A., "Application d'un modèle hybride à l'étude des dommages radio-induits par un faisceau d'électrons sur la molécule d'ADN dans son environnement", Radioprotection, vol. 43, pp. 357-387, 2008.

[7]- Oudira H., Djamai D., Saifi A., "Application d'un modèle déterministe à l'étude de l'influence des molécules radioprotectrices sur les rendements des cassures simple et double brin de la molécule d'ADN", Radioprotection, vol. 43, pp. 389-408, 2008.

[8]- W. Saenger., "Principles of nucleic acid structure", Ed. Springer-Verlag, New-York, 1984

[9]- Widom J., Towae d., "a unified model of chromatin folding", Annu, Rev Biohys. Chem., vol. 81, pp. 365-395, 1989.

[10]-Vrigneaud J.M., Ph.D, "Développement d'un modèle biophysique pour l'évaluation des dommages radio-induits dans la fibre chromosomique", (Université, CPAT de Toulouse, 2000).

[11]- D.E. Charlton and J.L. Humm, "A method of calculating initial DNA strand breakage following the decay of incorporated I ${ }^{125}$ ", Int.J.Radiat.Biol, vol. 53, pp. 353-365, 1985.

[12]- Pomplum E., Booz.J. et Charlon.D.E., "A Monte Carlo simulation of Auger cascades", Rad.Res, vol. 111, pp. 533-552, 1987. 